\title{
METAHEURISTIC ANALYSIS IN REVERSE LOGISTICS OF WASTE
}

\author{
Antonio Serrano Elena \\ Engineer PhD, University of Málaga, Spain
}

\begin{abstract}
ABSTRAT
This paper focuses in the use of search metaheuristic techniques on a dynamic and deterministic model to analyze and solve cost optimization problems and location in reverse logistics, within the field of municipal waste management of Málaga (Spain). In this work we have selected two metaheuristic techniques having relevance in present research, to test the validity of the proposed approach: an important technique for its international presence as is the Genetic Algorithm (GA) and another interesting technique that works with swarm intelligence as is the Particles Swarm Optimization (PSO). These metaheuristic techniques will be used to solve cost optimization problems and location of MSW recovery facilities (transfer centers and treatment plants).

Keywords: Reverse logistics, Optimization, Metaheuristics, Genetic Algorithm, Particles Swarm Optimization.
\end{abstract}

\section{INTRODUCTION}

The main objective of this paper is to develop the methodology and apply tools for modeling and solving the optimization of transfer costs of municipal solid waste (MSW) and its practical application in the optimization real problem and locating facilities in 90 municipalities in the province of Málaga. The scientific method is used to achieve these objectives, consisting of a review the state of art on reverse logistics, the selection of suitable metaheuristic techniques and application of modeling computer tool and selected resolution. The hypothesis to be proved is that the use of metaheuristics allows to solve this type of real problems where the exact algorithms can not.

\section{MATHEMATICAL MODEL DESIGN. OBJECTIVE FUNCTION}

For the design of the objective function we have been used some of models included in the classification given by Klose and Drexl (2000), the plant location work and heuristic use by Marin and Pelegrin (1991) and the contributions of Ortega Mier (2008). In Tables 2.1, 2.2 and 2.3 are indicated indexes, parameters and variables used in the proposed mathematical model.

\begin{tabular}{|c|l|r|}
\hline Index & \multicolumn{1}{|c|}{ Description } & \multicolumn{1}{|c|}{ Rank } \\
\hline$i$ & MSW producer municipalities & $1 \ldots M$ \\
\hline$j$ & MSW transfer centers & $1 \ldots N$ \\
\hline$k$ & MSW treatment plant & $1 \ldots P$ \\
\hline$t$ & Periods in years & $1 \ldots T$ \\
\hline
\end{tabular}


Table 2.1 - Indexes of the mathematical model.

\begin{tabular}{|c|l|}
\hline Parameters & \multicolumn{1}{|c|}{ Description } \\
\hline$P_{i t}$ & Production of waste in the municipality $i$ in year $t(T)$ \\
\hline$d_{i j}$ & Distance between municipalities $i$ and $j(k m)$ \\
\hline$d_{j k}$ & Distance between municipalities $j$ and $k(k m)$ \\
\hline$C T P_{t}$ & $\begin{array}{l}\text { Unit Cost of waste transfer between a transfer center and a treatment } \\
\text { plant ( } € / k m \cdot T) \text { in year } t\end{array}$ \\
\hline$C M T_{t}$ & $\begin{array}{l}\text { Unit Cost of transport of the waste collected in each municipality to the } \\
\text { transfer center }(€ / k m \cdot T) \text { in year } t\end{array}$ \\
\hline$Q T_{j t}$ & Annual capacity of the transfer center $j(T)$ in year $t$ \\
\hline$Q P_{k t}$ & Annual capacity of the treatment plant $k(T)$ in year $t$ \\
\hline$C F_{j t}$ & Fixed costs of the transfer center $j(€)$ in year $t$ \\
\hline$F_{k t}$ & Fixed costs of the treatment plant $k(€)$ in year $t$ \\
\hline
\end{tabular}

Table 2.2- Parameters of the mathematical model.

\begin{tabular}{|c|l|c|}
\hline Variable & \multicolumn{1}{|c|}{ Description } & Type \\
\hline$Z_{k t}$ & $\begin{array}{l}1 \text { if the treatment plant is located in the } \\
\text { municipality } k \text { during the year } t, 0 \text { otherwise }\end{array}$ & Binary \\
\hline$V_{j t}$ & $\begin{array}{l}1 \text { if the transfer center of the municipality } j \text { is open } \\
\text { during the year } t, 0 \text { otherwise }\end{array}$ \\
\hline$X_{i j t}$ & $\begin{array}{l}\text { Amount of waste transported from the } \\
\text { municipality } i \text { to the transfer center } j \text { during the } \\
\text { year } t\end{array}$ & Integer \\
\hline$Y_{j k t}$ & $\begin{array}{l}\text { Amount of waste transported from the transfer } \\
\text { center in the municipality } j \text { to the plant (in the } \\
\text { municipality } k \text { ) during the year } t\end{array}$ & Integer \\
\hline
\end{tabular}

Table 2.3 - Variables of the mathematical model.

The objective function is based on a dynamic model of multiple periods, with defined capacity and multiple origins, corresponding to a combinatorial optimization problem to minimize the total costs. This fitness function can be expressed as:

$$
F o=\min (F x+F y+F v+F z)
$$

Being:

$$
F x=\sum_{i j t} x_{i j t} d_{i j} C_{M T t}
$$


Subject to:

$$
\begin{aligned}
& F y=\sum_{j k t} y_{j k t} d_{j k} C_{T P t} \\
& F v=\sum_{j t} C F_{j t} v_{j t} \\
& F z=\sum_{k t} C F_{k t} z_{k t}
\end{aligned}
$$

$$
\begin{array}{ll}
R 1: \sum_{j}-x_{i j t} \leq-P_{i t} & \forall i, \forall t \\
R 2: x_{i j t} \leq P_{i t} v_{j t} & \forall i, \forall j, \forall t \\
R 3: \sum_{i j} x_{i j t} \leq \sum_{j} \quad Q T_{j t} v_{j t} & \forall t \\
R 4: \sum_{k} \quad y_{j k t} \leq \sum_{i} \quad x_{i j t} & \forall j, \forall t \\
R 5: y_{j k t} \leq z k P_{k t} & \forall j, \forall k, \forall t \\
R 6: \sum_{k}-z_{k t} \leq-1 a-90 & \forall t \\
R 7: \sum_{i j} x_{i j t} \leq \sum_{k} Q P_{k t} & \forall t
\end{array}
$$

With limits:

$$
\begin{array}{ll}
x_{i j t} \geq 0 & \forall i, \forall j, \forall t \\
y_{j k t} \geq 0 & \forall j, \forall k, \forall t \\
v_{j t} \in\{0,1\} & \forall j, \forall t \\
z_{k} \in\{0,1\} & \forall k
\end{array}
$$

The design of cost function (2.1) is defined by optimization (minimization) of the sum of transport costs (2.2) of all MSW collected from each municipality to transfer centers, transport costs (2.3) from each transfer center to treatment plants and fixed costs (2.4 and 2.5) transfer centers and treatment plants. Constraints (2.6) to (2.12) allow to bound the search of optimal cost to a more reduced convex space and indicate it should collect all MSW generated in each municipality and each period of time, ensuring that the waste collected and transported between municipalities, transfer centers and treatment plants do not exceed the capacity of facilities open during the period considered and guaranteeing a minimum number of treatment plants. The limits (2.13) to (2.16) bound the search for positive integer values of variables and indicate whether the facilities are open or closed.

It is a deterministic linear programming problem with mixed variables, in which the search for solutions becomes more complicated as increase the variables introduced being a NPhard problem (Garey and Johnson (1979)), for which a good solving policy is to use metaheuristics, since exact methods are unable of delivering any results at all in reasonable times (i.e. less than one year).

\section{MODELING AND RESOLUTION}

Genetic Algorithm (GA) set by Holland (1975) and particle swarm optimization (PSO) proposed by Kennedy and Eberhart (1995) are aplied on a real case of locating facilities of 90 municipalities in the province of Málaga. The code of these algorithms has been programmed with the MATLAB language allowing unify both exact and metaheuristic 
methods. Table 3.1 shows the data obtained with the different techniques used. In bold type are indicated the best times and fitness for instance. According to the results reflected, the exact methods used are insufficient to solve optimization problems with arrays of $90 \times 90 \times 5$.

\begin{tabular}{|c|c|c|c|c|c|}
\hline & Programs & Municipalities & Variables & Fval & Time(s) \\
\hline \multirow{4}{*}{ 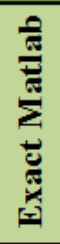 } & Tesisresiduos_6 & 6 & 84 & $9,64 \mathrm{E}+05$ & 0,33 \\
\hline & Tesisresiduos_20 & 20 & 4200 & $1,03 E+07$ & 0,47 \\
\hline & Tesisresiduos_40 & 40 & 16400 & $1,46 \mathrm{E}+07$ & 1,46 \\
\hline & Tesisresiduos_90 & 90 & 81900 & - & - \\
\hline \multirow{4}{*}{ 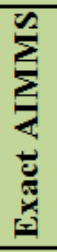 } & Tesisresiduos_6 & 6 & 84 & $9,64 \mathrm{E}+05$ & 0,01 \\
\hline & Tesisresiduos_20 & 20 & 4200 & $1,03 E+07$ & 0,05 \\
\hline & Tesisresiduos_40 & 40 & 16400 & $1,46 \mathrm{E}+07$ & 0,59 \\
\hline & Tesisresiduos_90 & 90 & 81900 & - & - \\
\hline \multirow{4}{*}{ 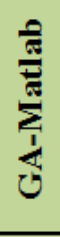 } & Tesisresiduos_6 & 6 & 84 & $9,98 \mathrm{E}+05$ & 4,59 \\
\hline & Tesisresiduos_20 & 20 & 4200 & $1,16 E+07$ & 48,07 \\
\hline & Tesisresiduos_40 & 40 & 16400 & $1,58 \mathrm{E}+07$ & 109,71 \\
\hline & Tesisresiduos_90 & 90 & 81900 & $2,37 \mathrm{E}+07$ & 170,86 \\
\hline \multirow{4}{*}{ 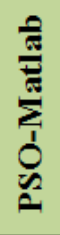 } & Tesisresiduos_6 & 6 & 84 & $1,24 \mathrm{E}+06$ & 0,17 \\
\hline & Tesisresiduos_20 & 20 & 4200 & $1,21 \mathrm{E}+07$ & 1,44 \\
\hline & Tesisresiduos_40 & 40 & 16400 & $1,50 \mathrm{E}+07$ & 4,14 \\
\hline & Tesisresiduos_90 & 90 & 81900 & $2,28 \mathrm{E}+07$ & 54,44 \\
\hline
\end{tabular}

Table 3.1 - Summary of results obtained with different techniques and municipalities.

The real problem to be solved is the optimization of a MSW collection network of 90 municipalities in the province of Málaga. MSW collected from different municipalities are transported to five transfer centers (Vélez-Málaga, Ronda, Cártama, Archidona and Campillos) and finally, valued and removed (if applicable) in treatment plants (Antequera and Casarabonela). On the described real scenario with the current location of each facility the hypothesis arises to restructure the network of waste collection, so that to minimize managing cost of these wastes applying equations designed and proposal metaheuristics. 

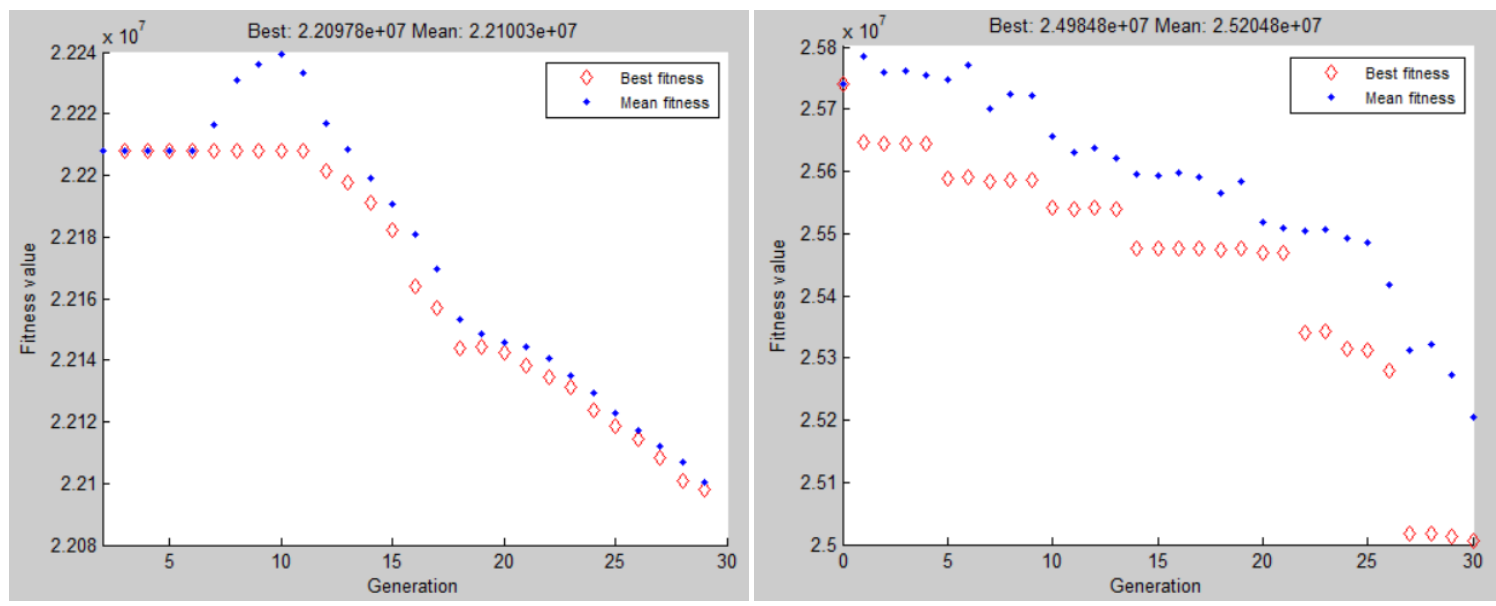

Figure 3.1 - Results of the best values of the fitness function for 1 execution PSO and GA for 30 generations and 90 municipalities.

Figure 3.1 shows the results obtained after a implementation with each metaheuristics for 90 municipalities. We have started with a population of 20 individuals and has established 30 generations before stopping the execution of algorithms.

PSO

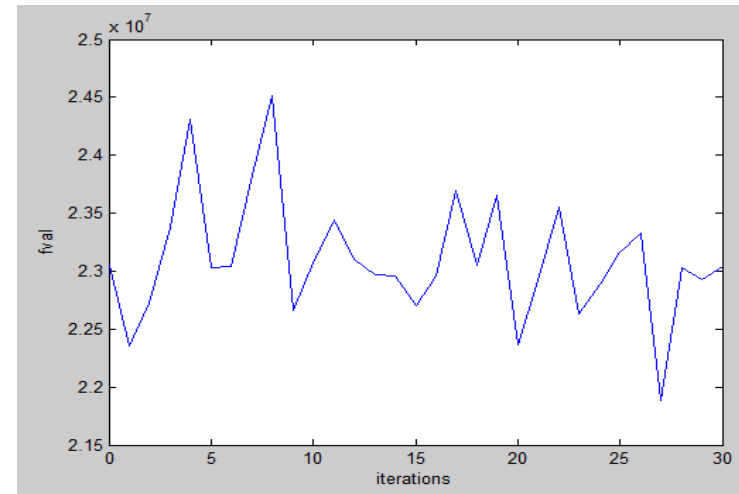

GA

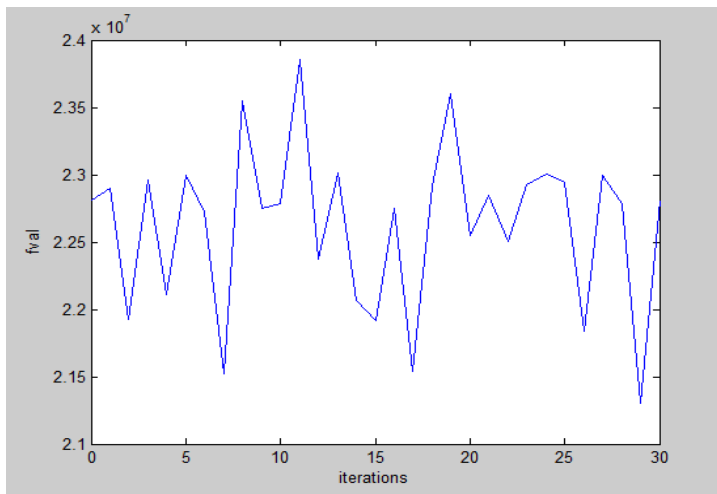

Figure 3.2 - Results of the best values of fitness function for 30 independent executions PSO and GA for 30 generations and 90 municipalities.

Figure 3.2 shows the evolution of the best values after 30 executions of each metaheuristics. The average values of these last executions correspond to the data shown in Table 3.1. Although the results obtained with both techniques are similar, the PSO algorithm is more efficient than the GA, to solve big problems (matrix of $90 \times 90 \times 5$ variables) with considerably less computational time and with the advantage of having a smaller number of parameters to configure.

A statistical verification of the above results has been performed by applying the test " $t$ student" for a sample. The test applies to sizes of 40 and 90 municipalities to be more significant. The contrast value in the case of 40 municipalities, is between the optimum 
reached with exact methods (30 samples equals) and the two metaheuristics. The results obtained with the "t-test" of MATLAB can be seen in Table 3.2.

\begin{tabular}{|c|r|r|r|r|r|}
\hline TEST T-STUDENT & Average v. fitness_GA/PSO & Null hypothesis value (h) & Probability (p-value) & \multicolumn{2}{|c|}{ Confidence interval (ci): $1.0 \mathrm{e}+05^{*}$} \\
\hline $\mathbf{9 0}$ municipalities:GA-PSO & $2.3663 \mathrm{e}+07 / 2.2822 \mathrm{e}+07$ & 1 & 0,008 & $-14,4550$ & $-2,3630$ \\
\hline $\mathbf{4 0}$ municipalities:GA-exact & $1.5190 \mathrm{e}+07 / 1.4631 \mathrm{e}+07$ & 1 & 0,0399 & 0,2750 & 10,8980 \\
\hline 40 municipalities:PSO-exact & $1.4997 \mathrm{e}+07 / 1.4631 \mathrm{e}+07$ & 1 & 0.0021 & 1,4566 & 5,9662 \\
\hline
\end{tabular}

\begin{tabular}{|c|r|r|r|}
\hline STATISTICS (stats) & Value test & Freedom degrees & Desviation \\
\hline $\mathbf{9 0}$ municipalities:GA-PSO & tstat: -2.8406 & df: 30 & sd: $1.6483 \mathrm{e}+06$ \\
\hline $\mathbf{4 0}$ municipalities:GA-exact & tstat: 2.1482 & df: 30 & sd: $1.4479 \mathrm{e}+06$ \\
\hline $\mathbf{4 0}$ municipalities:PSO-exact & tstat: 3.3616 & df: 30 & sd:6.1472e+05 \\
\hline
\end{tabular}

Table 3.2 - Results " $t$-student" for 40 and 90 municipalities with GA, PSO and Exact.

They are sampled 30 fitness values of each metaheuristic technique. The value of the null hypothesis in the three comparisons is 1 , which means than the contrasted samples are different from each other with an error probability lower of 5\%. The lower dispersion and average value shown by PSO in this statistical study confirm a better performance of this algorithm compared to GA. You can also see that the value of standard deviation $(s d)$ obtained for GA is greater than that obtained with PSO and the confidence interval ( $c i$ ) of GA is much more open than that of PSO. This means that PSO is more robust and reliable in practice for decision making.

Boxplot 6 municipalities

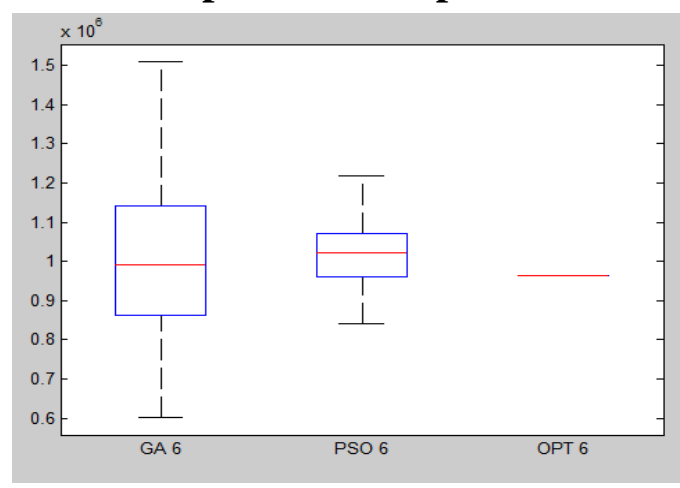

Boxplot 40 municipalities
Boxplot 20 municipalities

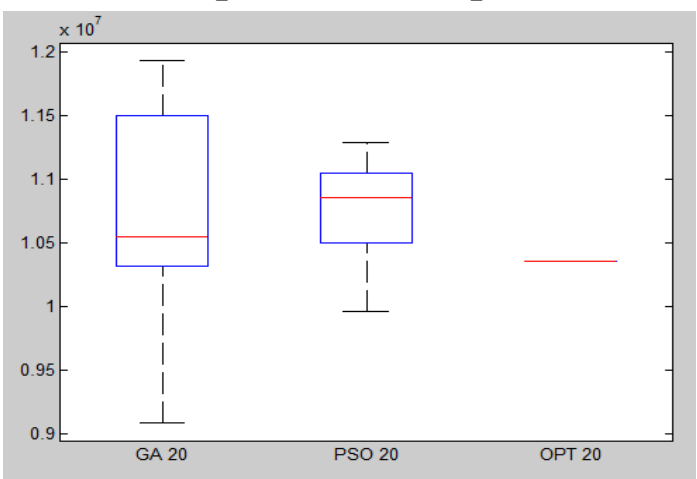

Boxplot 90 municipalities 

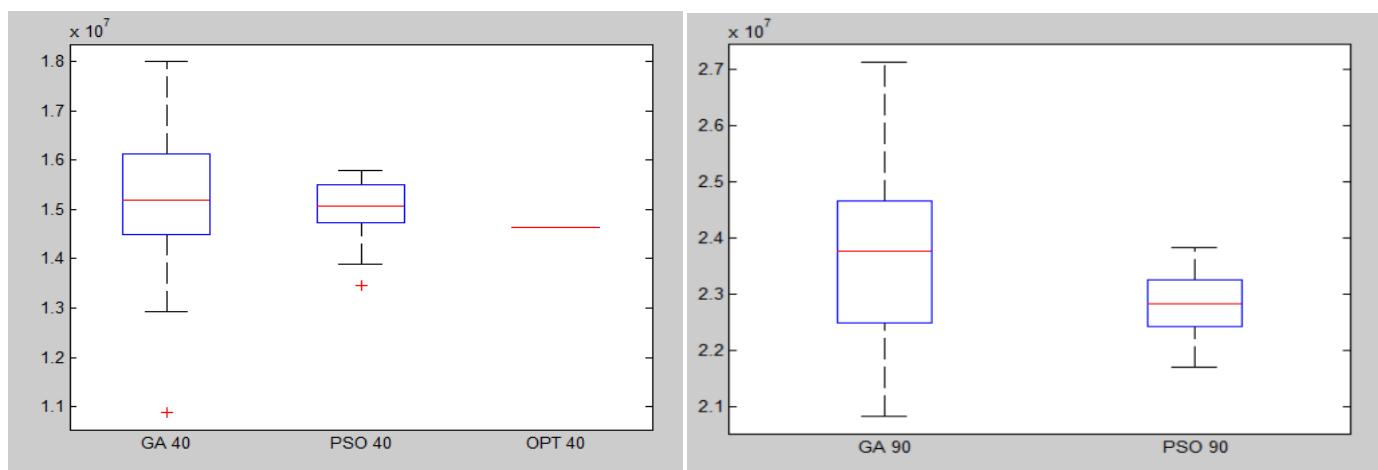

Figure 3.3 - Results "Boxplot" 6, 20, 40 and 90 municipalities with GA, PSO, Exact.

Figure 3.3 shows a graphical overview of the statistical results obtained by the "boxplot". The figure shows a comparison between the different metaheuristics techniques and the exact values for the different sizes of municipalities (6, 2040 and 90).

The results of statistical studies confirm the validity of two techniques used with values close to optimal. In general, the results obtained with GA are worse than those obtained with PSO because of higher dispersion defined by higher values of RIC (interquartile range) and also by standard deviation and confidence intervals greater. The results show that the PSO algorithm is more efficient searching the global optimum in a smaller feasible space in comparation with GA.

Table 3.3 shows current and actual MSW transport total costs since 90 municipalities until transfer centers and treatment plants. They are calculated according to the mathematical model designed and data provided by Deputation of Málaga. The calculations were performed for 2014 to facilitate comparison with the data obtained with metaheuristics.

\begin{tabular}{|c|c|c|c|c|c|}
\hline$X_{i j t} \cdot d_{i j t} \cdot C M T_{t}$ & $Y_{j k t} \cdot d_{j k t} \cdot C T P_{t}$ & $V_{j t} \cdot C F_{j t}$ & $\boldsymbol{Z}_{k t} \cdot \boldsymbol{C} \boldsymbol{F}_{k t}$ & $=$ & Total Cost \\
\hline 3.847 .807 & 756 & 985.360 & 430.276 & $=$ & 5.264 .199 \\
\hline
\end{tabular}

Table 3.3 - Cost 2014 of 90 municipalities according to current distribution.

The results obtained with metaheuristics used in this work and for the period 2014 can be seen in Table 3.4. These results demonstrate a savings of at least 740.000 euros (a reduction of $20 \%$ every year) in 2014 and a final savings for the analyzed period between 2010 and 2014 , close to 3,7 million euros. 


\begin{tabular}{|c|r|r|r|}
\hline PSO-GA & Municipalities & \multicolumn{1}{c|}{ Period } & \multicolumn{1}{c|}{ Total Cost } \\
\hline PSOtesisresiduos90_1 & 90 & 2014 & 4.522 .500 \\
\hline GAtesisresiduos90_1 & 90 & 2014 & 4.636 .400 \\
\hline
\end{tabular}

Table 3.4 - 2014 cost by applying algorithms PSO and GA for 90 municipalities.

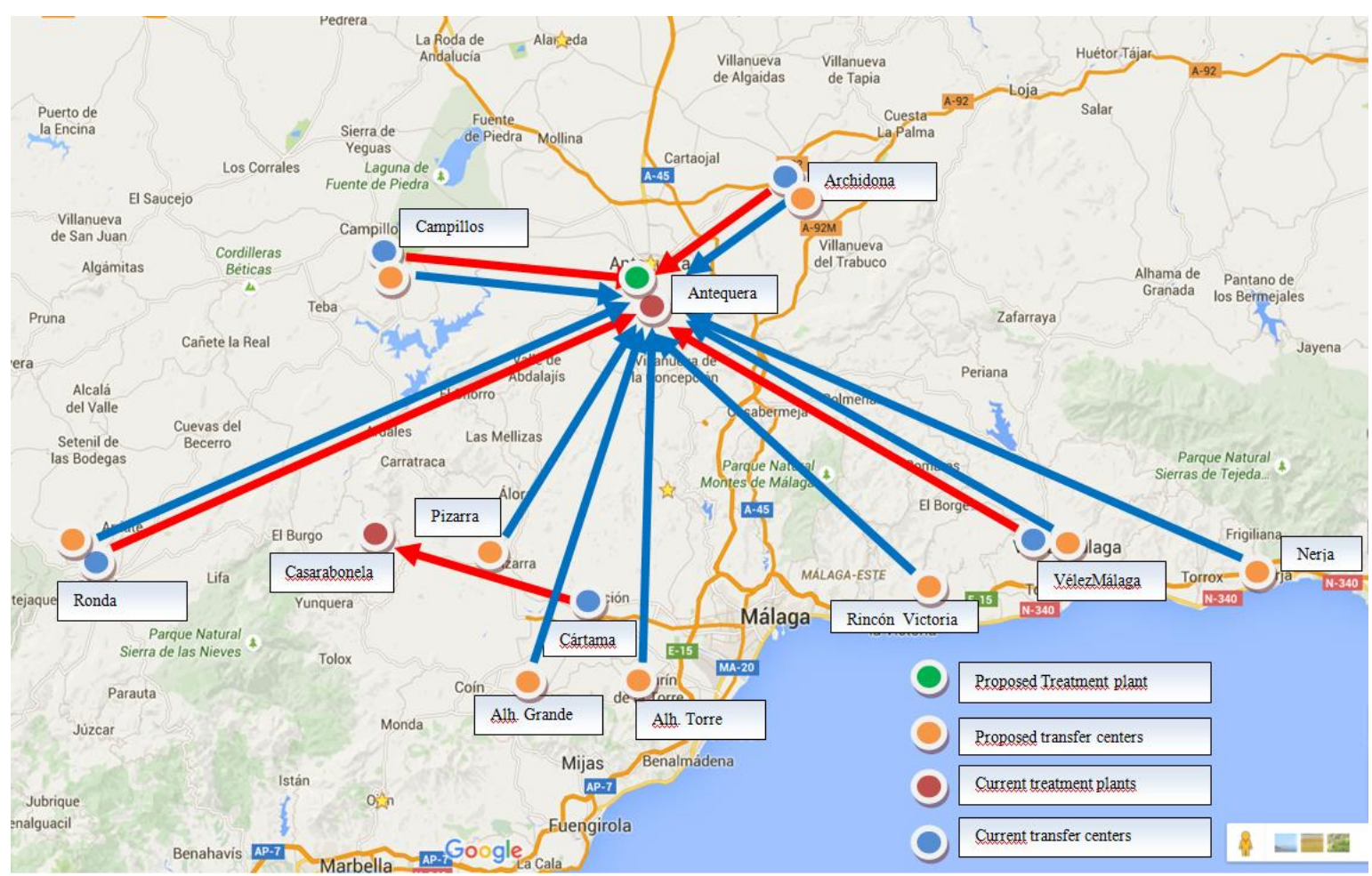

Figure 3.4 - Comparison between the current distribution and metaheuristic proposed, transfer centers and treatment plants in the province of Málaga.

Figure 3.4 shows as would be the new distribution of transfer centers (orange circle) and treatment plant (green circle) according to the results obtained with the best metaheuristic (blue line). the current status of transfer centers (blue circle), treatment plants (red circle) and waste transfers (red line) is also shown.

\section{CONCLUSIONS}

This research represents a breakthrough for the use of current metaheuristic as PSO unused so far in facility locations in reverse logistics. Likewise, the PSO algorithm has been more effective, faster and easier to program than GA. Are introduced considerations more realistic character than has generally been reported in the literature. This fact is shown in the results obtained with metaheuristics for the actual case of the 90 municipalities in the province of Málaga. Although there are many research about facility locations theory, we have found very few that propose, within the framework of reverse logistics, quantitative models of facility locations and use of metaheuristics techniques for solving an NP-hard 
problem accounting with real data.

\section{ACKNOWLEDGEMENTS}

This research is part of the $\mathrm{PhD}$ thesis developed in the Department of Economics and Business Administration and directed by PhDs Elvira Lopez Maeso and Enrique Alba Torres.

\section{REFERENCES}

Garey, M. R., y Johnson, D.S. (1979). Computers and Intractability. A Guide to the Theory of NP Completeness. W.H.Freeman, New York, NY.

Holland, J. (1975). Adaptation in Natural and Artificial Systems. MIT Press, Cambridge, MA, Estados Unidos.

Kennedy, Y.S.J. and Eberhart, R. (1995). Particle Swarm Optimization. Neural Networks, 1995. Proceedings. IEEE International Conference on Vol. 4, pp. 1942-1948.

Klose, A. y Drexl, A. (2005). Lower bounds for the capacitated facility location problem based on column generation. Management Science, 51, 1689-1705. Doi: 10.1287/mnsc. 1050.0410 .

Marín, A., Pelegrín, B. (1991). Heurísticas de descomposición lagrangiana para algunos problemas de localización discreta. Trabajos de Investigación Operativa, Vol. 7. 1, pp. $3-$ 15.

Ortega Mier, M.A. (2008). Utilización de métodos cuantitativos para el análisis de problemas de localización en Logística Inversa. Tesis Doctoral, Universidad Politécnica de Madrid. https://www.educacion.gob.es/teseo/mostrarRef.do?ref=559755. 